Crop Breeding and Applied Biotechnology 12: 138-144, 2012

Brazilian Society of Plant Breeding. Printed in Brazil

\title{
NOTE
}

\section{Meiotic irregularities in Capsicum L. species}

\author{
Margarete Magalhães Souza ${ }^{1 *}$, Telma Nair Santana Pereira ${ }^{2}$, Cláudia Pombo Sudré ${ }^{2}$ and Rosana Rodrigues ${ }^{2}$
}

Received 13 April 2010

Accepted 1 July 2010

\begin{abstract}
Cytogenetic and pollen viability $(P V)$ studies were performed in pepper accessions, Capsicum chinense and Capsicum baccatum. Irregularities such as laggard and univalent chromosomes, bridges, problems in the spindle fibers and cytomixis were observed, especially in $\mathrm{C}$. baccatum which was the most unstable genotype. In the post-meiotic products, irregularities were observed, on average, at $20 \%$ of the microspores in $\mathrm{C}$. baccatum and $17 \%$ in $\mathrm{C}$. chinense. PV in C. baccatum was below $70 \%$, while in $\mathrm{C}$. chinense, it was above $80 \%$. Meiotic irregularities in Capsicum, mainly in $\mathrm{C}$. baccatum, considering the low PV estimated, were significant but not impeditive for fertilization.
\end{abstract}

Key words: pepper, microsporogenesis, cytomixis, pollen viability.

\section{INTRODUCTION}

Capsicum baccatum $\mathrm{L}$. and C. chinense Jacq. are native to tropical and temperate regions in America, and were domesticated by native Americans (Moscone et al. 2007). The domesticated types are found around the world, while wild species have more limited distribution (Lanteri and Pickersgill 1993). Capsicum phylogenetic relationships, using evidences of chloroplastidic and nuclear DNA showed that, although being close, the species were grouped in different clades. Capsicum baccatum was included in the clade baccatum while $C$. chinense was included in the clade annuиm, and such results agree with groupings obtained based in morphology and isoenzymes (Choong 1998). Capsicum chinense presents great intraspecific genetic diversity (Fonseca et al. 2008).

Interspecific crossings have been performed in Capsicum species to elucidate the genetic relationships between them, and, mainly, to permit the genetic improvement of cultivars by introducing valuable alleles from wild accessions that are responsible, for example, for the resistance to pathogens, as obtained by Boiteux et al. (1993). The success of interspecific crossings is related to the genomic homology of parent species. For this kind of analysis, cytogenetic studies in domesticated or semi-domesticated Capsicum species and their ancestors have been performed (Lanteri and Pickersgill 1993). Cytogenetic investigations may reveal the proximity between species and genotypes through the observation of uniformity in chromosome pairing, or the distance between them, as observed in C. tovarii x C. baccatum hybrids that presented reciprocal translocations certifying the genetic distance between the parent species (Tong and Bosland 1999).

Meiosis is considered an event of high evolutional stability (Caetano-Pereira et al. 1998), but the occurrence of failures in the meiotic process, such as laggard chromosomes or the disorganization of the spindle fibers, are undesirable factors in the production of hybrids, as in Passiflora (Souza and Pereira 2011). Many times, the meiosis irregularities impinge a chromosome variation to new generations due to the loss or gain of chromosomes that generate unviable gametes, and it is not desirable when the parents are selected. In Solanum, pollen viability, a consequence of the regular meiosis, was used to identify the most appropriate genotypes for breeding programs (Tomé et al. 2007).

In Capsicum, meiotic and PG stainability analysis were performed to infer about the genetic relationship between two species (Kumar et al. 1988). Capsicum baccatum and

\footnotetext{
${ }^{1}$ Universidade Estadual de Santa Cruz (UESC), Departamento de Ciências Biológicas, Rod. Ilhéus-Itabuna, km 16, 45.662-900, Ilhéus, BA, Brazil. *E-mail: souzamagg@, yahoo.com.br

2 Universidade Estadual do Norte Fluminense Darcy Ribeiro (UENF), Centro de Ciências e Tecnologia Agropecuária, Av. Alberto Lamego, 2.000, 28.013-600, Campos dos Goytacazes, RJ, Brazil
} 
C. chinense $(2 n=24)$ are considered self-compatible, and usually these species do not present unilateral or crossed incompatibility (Nacio Onus and Pickersgill 2004). However, artificial crossings, performed between Capsicum baccatum L. and two accessions of Capsicum chinense Jacq., have resulted in very low fertilization rates. Thus, this work was performed to analyze the development of meiocytes, microspores and the pollen viability in Capsicum species for use in breeding programs.

\section{MATERIALS AND METHODS}

The studies were performed in three Capsicum L. accessions, C. baccatum L. (accession UENF-1417) and $C$. chinense Jacq. (accessions UENF-1418 and UENF-1419), conserved in the Capsicum collection maintained by Universidade Estadual do Norte Fluminense Darcy Ribeiro - UENF (Campos dos Goytacazes, RJ). These accessions were donated by Universidade Federal de Viçosa and have been used in the breeding program conducted by UENF.

\section{Meiotic and post-meiotic behavior}

For microsporogenesis studies, flower buttons were fixed in Carnoy I for 2 to 3 hours at room temperature and maintained at $-20{ }^{\circ} \mathrm{C}$. The slides were prepared with the squashing technique and cells were stained with $1 \%$ carmine. Five plants randomly sampled of each accession were analyzed; at least 50 cells of each meiotic phase analyzed were observed, per accession. The observation of chiasmata was performed in 20 cells per accession and used to obtain the recombination index $\left(\mathrm{RI}=\left[\sum\right.\right.$ total number of chiasmata $\div$ number of cells analyzed] $+n$ value; Darlington 1958). The bivalents were united by one or two chiasmata - the bivalent rods were scored as containing one chiasma while the bivalent rings as having two chiasmata (Senda et al. 2005). Then numbers of the post-meiotic products as monads, dyads, triads, tetrads and polyads were registered in order to calculate the meiotic index $(\% \mathrm{MI}=[$ number of normal tetrads x 100] $\div$ number of post-meiotic products counted; Love 1951) and to analyze the variance (Anova). Data were analyzed using the software Genes (Cruz 2006).

\section{Pollen Viability}

Pollen grains (PG) from recently opened flowers were collected and tested using the Alexander solution (Alexander 1969). The PG whose cytoplasm had stained and remained intact was considered viable. To prepare the slides, PG were delicately placed on a drop of stain, and after 5 minutes at room temperature, they were observed regarding to the morphological aspect and stainability, counted and measured. Five plants were analyzed (repetitions) per accession, and at least $500 \mathrm{PG}$ were counted per repetition/accession. The PG were classified into two types (Souza et al. 2003): type 1 (T1), empty (absence of cytoplasm), and type 2 (T2), contracted cytoplasm. The lengths of 50 viable and unviable PG per accession were measured using a micrometric ocular. Descriptive statistics and Anova were performed using the software Genes.

\section{RESULTS AND DISCUSSION}

\section{Meiotic behavior}

Meiotic irregularities were observed in accessions of pepper in all the analyzed phases. After the zygotene stage, groupings were observed characterizing pycnosis in the chromatin, sometimes near the cell wall of meiocytes, facilitating the intercell chromatin flow, cytomixis. In this stage, cytoplasmic connections between meiocytes and the passing of chromatin between cells were observed (Figure 1a), resulting in anucleate or two nuclei cells, and also cells with unbalanced number of chromosomes. As observed in C. baccatum and C. chinense, C. pubescens also presented pycnosis, however, leading to the degeneration of nuclear material in this species.

Cytomixis is an important factor to be considered in crossability analysis, because it alters the chromosomes number and leads to pairing irregularities and pollen sterility. Cytomixis is also considered a way to conserve genetic heterozygozity of the gametes (Veilleux 1985) and, according to Falistocco et al. (1995), it is important for the phylogenetic evolution of karyotypes due to the reduction or increase of ploidy, creating aneuploids and polyploids that, if successful, result in variability. Cytomixis may occur for many reasons, one of them is the action of genes (Kaul and Nirmala 1991). In Arabidiopsis thaliana, genes like the DIF1 (Bhatt et al. 1999), responsible for irregular meiotic chromosome segregation, have also been related to the cytomixis regulation (Bellucci et al. 2003).

The chromosome pairing expected for $C$. baccatum and C. chinense is 12 bivalents $(2 n=24 ; n=12)$ because they are diploid species, however univalents were observed, especially in C. baccatum; in C. chinense this percentage was lower (Figure 1b-c). Average percentages of chromosome pairing configurations 12 II and $10 \mathrm{II}+2$ I were, respectively: a) C. baccatum - 81.0 and 19.0; b) C. chinense UENF 1418 - 94.0 and 6.0 ; c) C. chinense UENF 1419 - 96.0 and 4.0. The species presented different percentages of laggard or precocious chromosomes (irregular segregation), univalents and bivalents, in all stages of meiosis (Figure 1d-f). Average percentage of cells with irregular segregation of univalents 


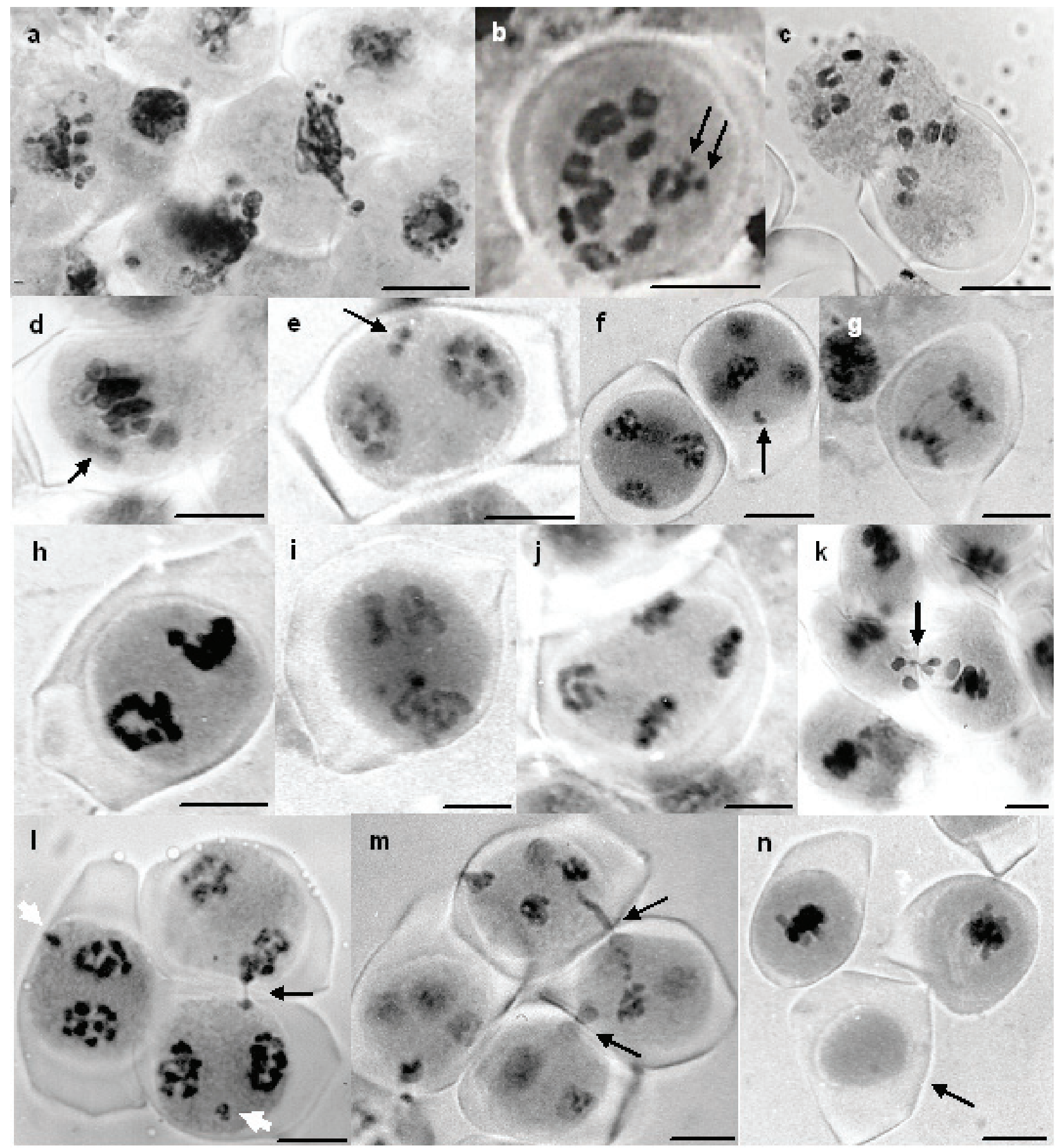

Figure 1. Meiotic irregularities in Capsicum species. a) Pycnosis after zygotene in C. chinense; b) Diakinesis with $11 \mathrm{~B}+2 \mathrm{U}$ (arrow) in C. baccatum; c) Diakinesis with $n=12$ in C. chinense; d) Irregular segregation at M I in C. baccatum; e) Univalents (arrow) at T I in C. chinense; f) Irregular segregation (arrow) persisting at T II in C. baccatum; g) Chromosome bridges at A I in C. chinense; g) Asynchrony at M II in C. baccatum; i) Asynchrony in $C$. baccatum showing anaphase and pre-metaphase in the same cell at meiosis II; j) A II in $C$. chinense with a chromosome set disorganized; $\mathbf{k}$ ) Cytomixis (arrow) at M I in C. chinense; l) Cytomixis (black arrow) at early T I in C. baccatum; disjointed chromosomes are observed (white arrow); m) Cytomixis (arrows) at T II in C. chinense; n) Anucleate cell (arrow) during M I in C. baccatum. Bar $=10 \mu \mathrm{m}$. 
and bivalents were, respectively: a) C. baccatum - metaphase I (M I) with 19.57 and 15.11, anaphase I (A I) with 18.10 and 12.32 , telophase I (T I) with 17.28 and $11.11, \mathrm{M}$ II with 18.48 and 8.43 , A II with 15.61 and 8.81 , T II with 9.42 and 5.32 ; b) C. chinense UENF 1418 - M I with 8.39 and 3.36, A I with 8.22 and 2.98, T I with 12.11 and 2.94, M II with 12.54 and 3.13, A II with 6.10 and 3.05, T II with 4.33 and 2.47 ; c) C. chinense UENF 1419 - M I with 10.93 and 6.25 , A I with 11.12 and 2.45, T I with 13.83 and 1.16, M II 12.07 and 2.25, A II with 14.42 and 2.56, T II with 4.58 and 2.38 .

C. baccatum obtained a higher percentage of irregular segregation, especially in meiosis I, while among $C$. chinense accessions the percentages of irregular segregation were lower in telophase II. During anaphase and telophase II, the percentage of lagging chromosomes decreased, suggesting that many of these chromosomes were reincorporated during meiosis II, probably due to the action of genes regulating nuclear restitution, which does not guarantee a viable final meiotic product.

Univalents were observed by Tong and Bosland (2003) in C. buforum and in C. lanceolatum, the latter in $33 \%$ of meiocytes in diakinesis, although no laggard chromosomes were observed in the following phases. Cawood and Jones (1980) observed not paired centrometers in bivalents of C. annuum that were still in diplotene, which can be an indication of precocius segregation of homologous, resulting in univalents in the other meiotic phases. According to Kumar et al. (1987), the presence of univalents can be a mechanism of genetic isolation in Capsicum. Shopova (1966) attributed the irregular segregation observed in $C$. annuum, $C$. frutescens and $C$. pubescens to DNA breaks which occurred during pycnosis in these species.

Interstitial chiasmata were predominant in all cells from all accessions studied. Average number of terminal, interstitial and total chiasmata per cell observed in diakinesis were, respectively: a) C. baccatum - 3.1, 9.0 and 12.05; b) C. chinense UENF $1418-3.2,8.8$ and 12.1 ; c) C. chinense UENF $1419-8.7,6.9$ and 15.6. The RI varied between $C$. chinense accessions. Average number of recombination index were 24.05 in C. baccatum, 24.1 in C. chinense UENF 1418 and 27.6 in C. chinense UENF 1419. According to the variance analysis, there was a significant difference at the $1 \%$ $(\mathrm{P}<0.01)$ probability level by test $\mathrm{F}$ between the accessions for the following characteristics: number of terminal chiasmata, number of interstitial chiasmata and total number of chiasmata. Kumar et al. $(1987,1988)$ observed, on average, 19.64 chiasmata per nucleus in $C$. chinense, with minimum and maximum values between 17 and 24. Different numbers of chiasmata per nucleus were observed in C. baccatum, 18.1 to 20.5 (Rao et al. 1992), 17 to 22 (Kumar et al. 1987) and 10 to 22 (Tong and Bosland 1999). In C. baccatum and $C$. chinense genotypes studied, the average number of chiasma per nucleus observed was lower than the ones reported by other authors, varying from 11 to 13 in C. baccatum and from 9 to 17 in C. chinense.

Interstitial chiasmata (one per bivalent) prevailed in all accessions of both species, which decreases the recombination index. In the accessions studied, the low number of chiasmata may have been the cause for the univalents observed. Lein and Lelley (1987) have reported that the chiasmata frequency and location are under polygenic control. If a genic segregation occurs, different frequencies of chiasmata may be observed (Defani-Scoarize et al. 1996), but a little is known about the genetic control of chiasmata. In C. baccatum and C. chinense accessions analyzed, the low frequency of chiasmata and the transfer of portions of chromatin from one cell to another in different phases of meiosis may have been the cause of laggard chromosomes and, consequently, of micronuclei in microspores, and of binucleate pollen grains.

Chromosome bridges were observed (Figure 1g) in meiocytes of C. baccatum and in C. chinense UENF 1418 and UENF 1419 accessions. Average percentage of cells with bridges were: a) C. baccatum - 5.28 in A I, 3.65 in A II; b) C. chinense UENF 1418 - 4.71 in A I, 1.92 in A II; c) C. chinense UENF 1419-3.98 in A I, 2.34 in A II. Asynchrony was observed in all phases of meiosis II, when in the same cell both chromosome sets presented different arrangements (Table 3 ; Figure $1 \mathrm{~h}-\mathrm{j}$ ). Average percentage of cells with asynchrony were: a) C. baccatum - 22.55 in M II, 15.74 in A II, 5.28 in T II; b) C. chinense UENF $1418-14.20$ in M II, 11.29 in A II, 2.26 in T II; c) C. chinense UENF $1419-19.58$ in M II, 12.66 in A II, 3.19 in T II. In over $30 \%$ of cells at meiosis I and II in C. baccatum and C. chinense, cytoplasmic connections and the exchange of chromosome material between meiocytes were observed (Figure $1 \mathrm{k}-\mathrm{m}$ ), most of the time involving chromosomes located next to the walls, as well as empty meiocytes (Figure 1n), due to cytomixis observed in these species.

According to Lanteri and Pickersgill (1993), rearrangements in the genome seem to be associated with the evolution and differentiation of many Capsicum species when the chromosome exchanges are reciprocal. Only one persistent bridge, without fragments, was observed in each $C$. baccatum and $C$. chinense meiocyte with this irregularity, suggesting heterozygote inversion (Kumar et al. 1987), probably because these accessions come from improved generations. 
Abnormality in the formation of the spindle and asynchrony in meiosis II affected the post-meiotic products. Depending on which type of irregularity that occurs in the cell, the spindles may group or separate homologous chromosomes (CaetanoPereira et al. 1998), and result in meiocytes with trinucleate telophase II, or even with cells presenting the division of non-equational cytoplasm due to the unbalanced number of chromosomes, as observed in the studied accessions. In Zea, irregularities in the spindle are caused by genetic factors, and in some populations, mutants with genes $d v$ (divergent spindle) (Golubovskaya and Mashnenkov 1981), ms43 (absence of the second meiotic division due to a disturbance in the spindle orientation) and $m s 28$ (late depolymerization of the spindle fibers) (Golubovskaya 1989) were observed.

\section{Post-meiotic behavior}

At the end of meiosis, irregularities (Figure 2) and MI (\%) in C. baccatum and C. chinense UENF 1418 and UENF 1419 accessions were also observed, respectively: a) monads $-0.8,0.2$ and 0.3 ; b) dyads $-0.5,0.4$ and 0.4 ; c) triads $-12.7,9.7$ and 10.9 ; d) polyads $-9.3,7.2$ and 6.6 ; MI - 76.5, 82.4 and 81.7. Triads were the most observed

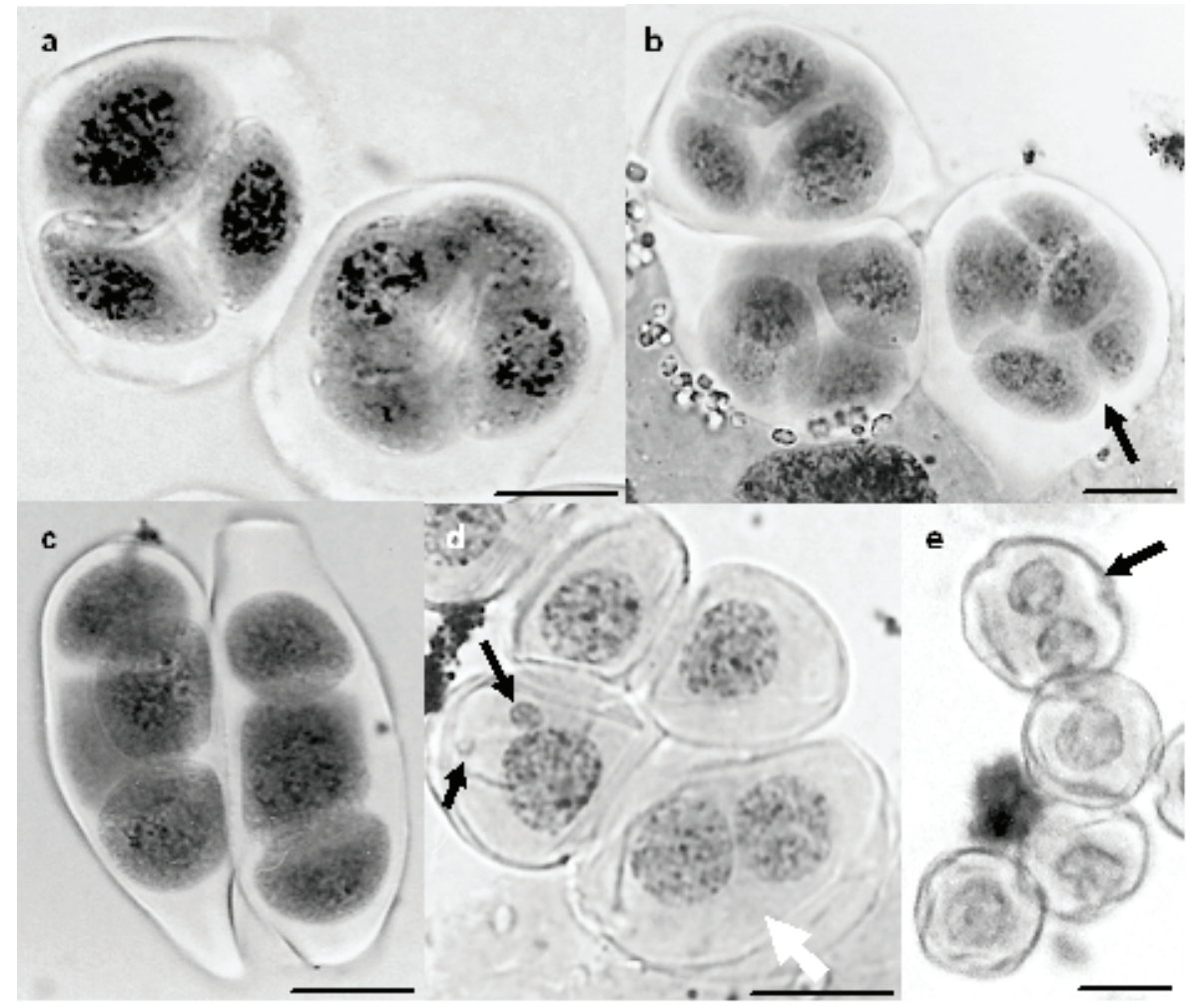

Figure 2. Irregular post-meiotic products in Capsicum species. a) Normal tetrad and triad in C. chinense; b) Normal tetrad and polyad (arrow) with cell of different sizes in C. baccatum; c) Linear tetrads in $C$. baccatum; d) Microspore with micronuclei (arrow) and binucleate (white arrow) in C. baccatum; e) Normal microspores and PG binucleate (arrow) in C. chinense. Bar $=20 \mu \mathrm{m}$.. irregular product, probably due to the asynchrony during meiosis II, which disturbs chromosome segregation (Souza and Pereira 2011).

While tetrads of the tetrahedral type were normally observed, some linear tetrads were found only in C. baccatum (Figure 2c). Some microspores presented one or more micronuclei, while others were bi-nucleated (Figure 2d). Irregular chromosome segregation in meiosis I and II could be the result of the non-oriented chromosomes, which show an inability to congregate on the equatorial plate, resulting in the grouping of the many sets of chromosomes in telophase II, as well as micronuclei, incorrect cytoplasm division and polyads (Souza and Pereira 2011).

\section{Pollen viability}

The pollen viability in C. baccatum was below $70 \%$, while in $C$. chinense, both accessions presented pollen viability above $80 \%$. The frequency of viable and unviable $\mathrm{PG}$ in relation to the pollen length is presented in the Figure 3. In the analyzed species, the highest frequency of viable PG was measured between 32-34 $\mu$ m, while for the unviable $\mathrm{PG}$ there was a size variation $(20-28 \mu \mathrm{m})$ between types $\mathrm{T} 1$ and $\mathrm{T} 2$ and between the accessions. The PG average length between unviable T1 and $\mathrm{T} 2$ varied $5 \%$ in $C$. baccatum, $17.8 \%$ in $C$. chinense UENF 1418 accession, and $6.1 \%$ in $C$. chinense UENF 1419. The difference in percentage between the average length of unviable and viable PG was higher, being 29.7 $\%$ in C. baccatum, $22.8 \%$ in $C$. chinense UENF 1418 accession, and $33.5 \%$ in $C$. chinense UENF 1419. Some binucleate PG was observed (Figure 2e).

The MI in C. baccatum (76.5 $\%$ ) was lower than in $C$. chinense accessions (80\%). However, the pollen viability $(\mathrm{PV})$ was even lower in C. baccatum, 65.7 \%, while in C. chinense were above $88 \%$. The percentage of the PV is different between accessions of Capsicum species. Tong and Bosland $(1999,2003)$ observed $\mathrm{PV}$ above $96 \%$ in accessions of $C$. 

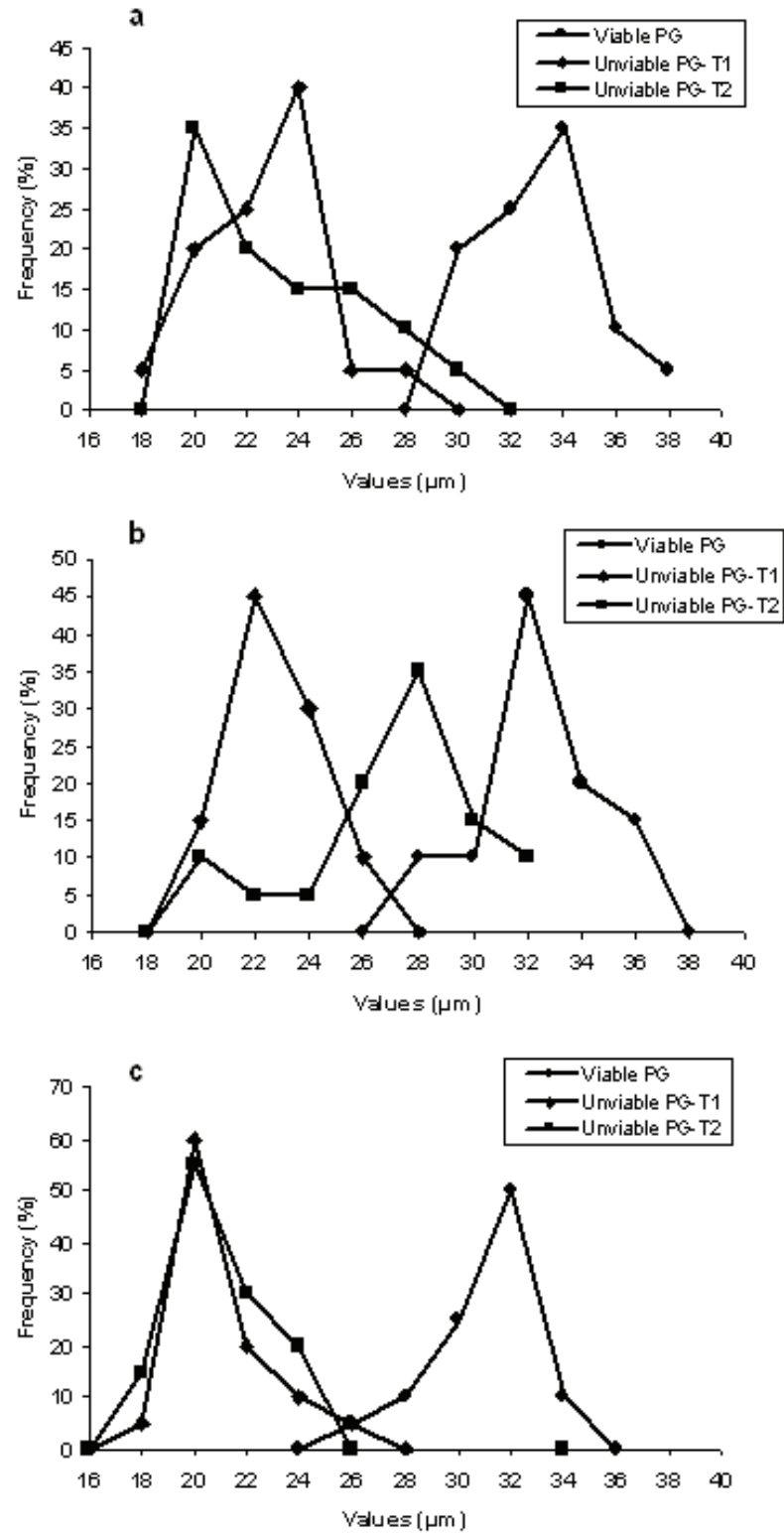

Figure 3. Viable and sterile pollen grains (PG) in relation to PG size in Capsicum accessions. a) C. baccatum; b) C. chinense UENF 1418; c) C. chinense UENF 1419. baccatum, and regular meiosis. In C. chinense, PV percentages were between 84 to $87 \%$, being $60 \%$ from unviable $\mathrm{PG}$, type T1, however, multivalents were observed during the chromosome pairing (Lanteri and Pickersgill 1993). Dharamadhaj and Prakash (1978) attributed the variation found in the PV percentage in Capsicum species to environmental influence and observed pollen fertility above 90 $\%$ in the summer, while in the winter the same accessions presented a maximum pollen fertility of $31 \%$.

In the accessions studied, the values of MI and PV observed suggest that in C. baccatum the low PV occurred, mainly, due to meiotic irregularities, since the majority of unviable PG is type T1, empty, with a maximum of $24 \mu \mathrm{m}$ and $30 \%$ of the size of the viable PG. The pollen sterility deserves attention in breeding programs because in some cases the unviable T1 PG may occur due to genic mutations (Twell 1995). However, not only the irregularities observed during meiosis, but also post-meiotic factors were responsible for the pollen sterility. In both $C$. chinense accessions, the percentages observed of unviable T2 PG, contracted, were higher than those of T1 PG, measuring up to $34 \mu \mathrm{m}$. Thus, it is suggested that the sterility of type 2 occurred during the gametophytes development, probably starting in the microspore stage, while those of type 1 are aborted in the beginning of their development.

Among the three accessions analyzed, C. baccatum demonstrated higher meiotic instability. The irregular chromosome pairing, univalents, chromosome bridges and laggards in anaphase I resulted in a lower meiotic index and higher pollen non-viability. These results indicated that the analyzed $C$. baccatum accession suffered small chromosome alterations in the process of domestication and improvement, and that its genome is structurally different from the analyzed $C$. chinense accession.

\section{ACKNOWLEDGEMENTS}

The authors thank Fundação Estadual do Norte Fluminense (FENORTE) for financial support and Gisele Azevedo Picanço Dutra for collaboration in the sample collection.

\section{Irregularidades meióticas em espécies de Capsicum $\mathbf{L}$.}

Resumo - Estudos citogenéticos e de viabilidade polinica (VP) foram realizados em acessos de pimenta de Capsicum chinense $e$ Capsicum baccatum. Irregularidades tais como cromossomos retardatários e univalentes, pontes, problemas na formação das fibras dos fusos e citomixia foram observados, especialmente em C. baccatum, que foi considerado o genótipo mais instável. Nos produtos pós-meióticos foram observadas irregularidades tais como tríades e políades em $20 \%$ dos micrósporos de C. baccatum e em $17 \%$ dos micrósporos de C. chinense, em média. VP em C. baccatum foi abaixo de $70 \%$, enquanto C. chinense apresentou VP acima de 80 $\%$. Irregularidades meióticas em Capsicum, principalmente em C. baccatum, considerando a baixa VP estimada, foram significativas, mas não impeditivas para ocorrência de fertilização.

Palavras-chave: pimenta, microsporogênese, citomixia, viabilidade polínica. 


\section{REFERENCES}

Alexander MP (1969) Differential staining of aborted and nonaborted pollen. Stain Technology 965: 117-122.

Bellucci M, Roscini C and Mariani A (2003) Cytomixis in pollen mother cells of Medicago sativa L. Heredity 94: 512-516.

Bhatt AM, Lister C, Page T, Fansz P, Findlay K, Jones GH, Dickinson $\mathrm{HE}$ and Dean C (1999) The DIFl gene of Arabidopsis is required for meiotic chromosome segregation and belongs to the Rec8/RAD21 cohesion gene family. Plant Journal 19: 463-472.

Boiteux LS, Nagata T, Dutra WP and Fonseca MEN (1993) Sources of resistance to tomato spotted wild virus (TSWV) in cultivated and wild species of Capsicum L. Euphytica 67: 89-94.

Caetano-Pereira CM, Defani-Scoarize MA, Pagliarini MS and Brasil EM (1998) Syncytes, abnormal cytokinesis and spindle irregularities in maize microsporogenesis. Maydica 43: 235-252.

Cawood AH and Jones JK (1980) Chromosome behavior during meiotic prophase in the Solanaceae. Chromosoma 80: 57-68.

Choong CY (1998) DNA polymorphisms in the study of relationships and evolution in Capsicum. University of Reading, Berkshire, 120p.

Cruz CD (2006) Programa Genes: estatística experimental e matrizes. Editora UFV, Viçosa, 430p.

Darlington CD (1958) Evolution of genetic systems. Oliver and Boyd, London, 340p.

Defani-Scoarize MA, Pagliarini MS and Aguiar CG (1996) Meiotic behavior of inbred lines of maize (Zea mays L.). Nucleus 39: 10-18.

Dharamadhaj P and Prakash N (1978) Development of the anther and ovule in Capsicum L. Australian Journal of Botany 26: 433-439.

Falistocco E, Tosti N and Falcinelli M (1995) Cytomixis in pollen mother cells of diploid Dactylis, one of the origins of $2 n$ gametes. Cytologia 86: $448-453$.

Fonseca RM, Lopes R, Barros WS, Lopes MTG and Ferreira FM (2008) Morphologic characterization and genetic diversity of Capsicum chinense Jacq. accessions along the upper Rio

Golubovskaya IN (1989) Meiosis in maize: mei genes and conception of genetic control of meiosis. Advances in Genetics 26: 149-192.

Golubovskaya IN and Mashnenkov AS (1981) Genetic control of chromosome segregation during the first meiotic division. Maize Genetics Cooperation Newsletter 55: 78-81.

Kaul MLH and Nirmala C (1991) Male sterile gene action diversity in barley and pea. Nucleus 34: 32-39.

Kumar OA, Panda RC and Rao KGR (1987) Cytogenetic studies of the $\mathrm{F}_{1}$ hybrids of Capsicum annuum with $C$. chinense e C. baccatum. Theoretical and Applied Genetics 74: 242-246.

Kumar OA, Panda RC and Rao KGR (1988) Cytogenetics of interspecific hybrids in the genus Capsicum L. Euphytica 39: 47-51.
Lanteri S and Pickersgill B (1993) Chromosomal structural changes in Capsicum annum L. and C. chinense Jacq. Euphytica 67: 155-160.

Lein V and Lelley T (1987) A separate control for frequency and withinbivalent distribution of chiasmata in rye (Secale cereale L.). Genome 29: 419-424.

Love RM (1951) Varietal differences in meiotic chromosomes behavior of Brazilian wheats. Agronomy Journal 43: 72-76.

Moscone EA, Scaldaferro MA, Grabiele M, Cecchini NM, García YS, Jarret R, Daviña JR, Ducasse DA, Barboza GE and Ehrendorfer F (2007) The evolution of chili peppers (Capsicum - Solanaceae): a cytogenetic perspective. Acta Horticulturae 745: 137-169.

Naci Onus A and Pickersgill B (2004) Unilateral incompatibility in Capsicum (Solanaceae): occurrence and taxonomic distribution. Annals of Botany 94: 289-295.

Negro-Amazonas. Crop Breeding and Applied Biotechnology 8: 187194.

Rao NB, Srivalli T and Lakshmi N (1992) Cytogenetic studies on the interspecific hybrid Capsicum baccatum L. x C. frutescens $\mathrm{L}$. and its progeny. Euphytica 59: 135-140.

Senda T, Hiraoka Y and Tominaga T (2005) Cytological affinities and interfertilities between Lolium temulentum and L. persicum (Poaceae) accessions. Hereditas 142: 45-50.

Shopova M (1966) Studies in the genus Capsicum: II. Irregularities in the pollen mother cells. Chromosoma 19: 349-356.

Souza MM and Pereira TNS (2011) Meiotic behavior in wild and domesticated species of Passiflora. Revista Brasileira de Botânica 34: $63-72$.

Souza MM, Pereira TNS, Viana PV, Pereira MG, Bernacci LC, Sudré CP and Silva LC (2003) Meiotic irregularities and pollen viability in Passiflora edmundoi Sacco (Passifloraceae). Caryologia 56: 161-169.

Tomé LGO, Davide LC, Pinto CABP, Alves AA and Salgado CC (2007) Pollen viability and meiotic analysis of Solanum commersonii commersonii Dun., Solanum commersonii malmeanum Bitt. and Solanum tuberosum L. Crop Breeding and Applied Biotechnology 7: 387-393.

Tong N and Bosland PW (1999) Capsicum tovarii, a new member of the Capsicum baccatum complex. Euphytica 109: 71-77.

Tong N and Bosland PW (2003) Observations on interspecific compatibility and meiotic chromosome behavior of Capsicum buforum and $C$. lanceolatum. Genetic Resource and Crop Evolution 50: 193-199.

Twell D (1995) Diphtheria toxin-mediated cell ablation in developing pollen: vegetative cell ablation blocks generative cell migration. Protoplasma 187: 144-154.

Veilleux R (1985) Diploid and polyploid gametes in crop plants: mechanism of formation and utilization in plant breeding. Plant Breeding Reviews 3: 253-288. 